\title{
HBA1C as a Dual Marker for the Detection of Lipid Profile and Cardiovascular Disease in Type-II Diabetic Subjects
}

\author{
Ahmad Sadiq ${ }^{1}$, Muzafar Shah ${ }^{2 *}$, Habib Ullah', Irfan Ali', Amir Alam ${ }^{3}$, \\ Navid Jalil ${ }^{1}$ and Muhammad Khan ${ }^{3}$ \\ ${ }^{1}$ Department of Zoology, Government College Daggar Buner, University of Swat, \\ Pakistan \\ ${ }^{2}$ Centre for Animal Sciences and Fisheries, University of Swat, Pakistan \\ ${ }^{3}$ Department of Zoology, Hazara University, Mansehra, Pakistan
}

\begin{abstract}
A B S T R A C T
Diabetic patients are deliberated to be at greater risk of hypertension and lipid abnormalities, which are the main cause of cardiovascular diseases (CVD). The present work revealed the role of glycated hemoglobin (HbA1c) for the detection of lipid profile and CVD. In recent study 108 (56 males and 52 female) type 2 diabetes (T2DM) subjects were diagnosed at Hayatabad Medical Complex (HMC) Peshawar and private diabetic clinic "Khattak Medical Centre" (KMC), Dabgari Garden Peshawar, Khyber Pakhtunkhwa, Pakistan. The normal or control group consists of twenty ( 9 females and 11 males) people having no history of diabetes mellitus, hypertension and cardiovascular disease. Glycated hemoglobin HbA1c, random blood sugar (RBS) triglycerides (TG) total cholesterol (TC) systolic blood pressure (SBP) and diastolic blood pressure (DBP) were significantly higher in patients $(\mathrm{p}<0.05)$ than normal or controlled. In patients with low density lipoprotein (LDL), high density lipoprotein (HDL) and body mass index (BMI) were found to be significantly lower $(p>0.05)$ than normal or control. Gender-based analysis has shown that HbA1c, RBS, DBP and SBP in male patients have significantly higher $(p<0.05)$ than female. But in female patients the TC, TG and BMI are insignificantly higher $(\mathrm{p}<0.05)$ compared to male. High density lipoprotein (HDL) was found same in both male and female. Moreover, patients with HbA1c $>7$ have $26.66 \%$ stroke, $4.44 \%$ angina, $2.22 \%$ ischemic heart disease and $27.77 \%$ micro vascular complications.
\end{abstract}

\begin{tabular}{l} 
Article Information \\
\hline Received 11 September 2019 \\
Revised 04 November 2019 \\
Accepted 13 November 2019 \\
Available online 26 February 2021 \\
Authors' Contribution \\
\hline AS, HU, IA and AM carried our \\
research work, NJ and MK worked on \\
analysis \& MS wrote the Manuscript. \\
Key words \\
Diabetes mellitus, Hyperglycemia, \\
Cardiovascular, Lipid, Peshawar, \\
Buner
\end{tabular}

\section{INTRODUCTION}

$\mathrm{D}$ iabetes mellitus (DM) is a metabolic condition, characterized by high blood glucose level resulting from imperfect secretion of insulin, insulin action or both. Diabetes mellitus type $2(\mathrm{~T} 2 \mathrm{DM})$ is a challenging disorder in between $85-90$ percent of all the cases of diabetes (Hassan et al., 2004). The chronic hyperglycemia of diabetes is associated with long-term damage, dysfunction and failure of various organs, especially the eyes, kidneys, nerves, heart and blood vessels (Uttra et al., 2011). Impairment in uptake of glucose by muscles, elevated level of endogenous glucose production by the liver are the key features of insulin resistance which result in hyperglycemia (Fabbrini et al., 2010). It is associated with microvascular and macrovascular complications. Advanced glycation end product's (AGEs) formation and deposition in different

\footnotetext{
* Corresponding author: muzafar@uswat.edu.pk 0030-9923/2021/0002-0699 \$ 9.00/0

Copyright 2021 Zoological Society of Pakistan
}

tissues is accelerated by chronic hyperglycemia in T2DM (Uribarri and Tuttle, 2006). The T2DM has many complex causes which involve different metabolic factors such as over eating, obesity, cardiovascular diseases (CVD) (dyslipidemia, hypertension), physical inactivity and some uncontrollable genetic factors and family history (Boon, 2006). The earlier onset of the diabetes in children and adolescents is caused by the increasing rate of obesity (Cheng, 2005).

CVD is a wide class of diseases, including coronary heart diseases, peripheral arterial disease, stroke and aortic disease. About $50 \%$ of diabetic individuals die due to CVD (WHO, 2013). Obesity has been recognized as a metabolic risk factor and causes insulin resistance (Tchernof and Despres, 2013). Diabetic individuals have two to four time higher risks for coronary heart disease than non-diabetic individuals (Kannel and McGee, 1979). Glycosylated hemoglobin (HbAlc) is used as a reliable tool for the diagnosis of diabetes (IEC, 2009). The diabetes complications and controls trails (DCCT)suggested that $\mathrm{HbA} 1 \mathrm{c}$ be a normal glycemic control test with levels 7 
percent considered appropriate to reduce the likelihood of vascular complication (Gotto, 2007).It reflects average plasma glucose over the previous eight (8) to twelve (12) weeks and used as a biomarker for the prediction of dyslipidemia in T2DM subjects (Naeem et al., 2016). The pathogenicity of coronary artery disorder can be reduced by controlling glycosylated $\mathrm{HbAlc}$ in T2DM subjects (Warnick et al., 1990). High level of glycated $\mathrm{HbA} 1 \mathrm{c}$ has now been shown an independent risk factor for cardiovascular disorders in both diabetics and nondiabetic population (ADA, 2004).

Several other observations also estimated that the risk of mortality is increased by $25 \%$ and risk of macrovascular complications by $35 \%$ for each one percent increase in HbA1c in diabetic population (Sankha, 2016). Current study was therefore conducted in T2DM patients to examine the role of $\mathrm{HbA} 1 \mathrm{c}$ and lipid profile in the detection of CVD events.

\section{MATERIALS AND METHODS}

The current study was conducted during a period of January 2017 to April 2017 in Peshawar, Khyber Pakhtunkhwa. Samples were collected from Hayatabad Medical Complex (HMC) and Private diabetic clinic (Khattak Medical Centre), Dabgari Garden Peshawar, Khyber Pakhtunkhwa. A total of 108 patients $(\mathrm{Male}=56$, Female $=52$ ) with T2DM were selected, who visited hospital/ clinic and already diagnosed and undergoing treatment. 20 subjects $($ Male $=11$, Female $=9$ ) were pointed out as control and samples were collected from them. Those patients having diagnosed T2DM and visiting hospitals/ clinic for other complications were included but those patients having gestational diabetes and T1DM were excluded from the study. For control subjects having no history of CVD, DM and hypertension were considered as control.

\section{Ethical consideration}

The study has been approved by the Department of Zoology Ethical Committee, Govt. Degree College Dagger, affiliated with University of Swat, Khyber Pakhtunkhwa, Pakistan. Furthermore, a written consent was obtained from the Medical Superintendent (MS) of the above mentioned hospitals where samples were collected. Informed consents were obtained from the control subjects and patients.

\section{Laboratory investigation}

A $3 \mathrm{ml}$ blood sample was taken from each subject. For HbA1c and RBCs count $1 \mathrm{ml}$ of blood was stored in EDTA tube while $2 \mathrm{~mL}$ of blood was taken in fluoride oxalate tube (To prevent glycolysis) for serum lipid profile and Random Blood Sugar (RBS). All the blood samples were analyzed in diagnostic laboratory of HMC, Peshawar. To separate the serum for further investigation the blood were centrifuged at 3,500 rpm for $5 \mathrm{~min}$. The blood pressure was expressed in $\mathrm{mmHg}$, unit for lipid and glucose profile were expressed by $\mathrm{mg} / \mathrm{dl}$ and $\mathrm{HbAlc}$ has been expressed in percentage. HbAlc was determined by turbidimetric inhibition immunoassay (TINIA) using automated hematology analyzer Cobas C 111 (Roche, Germany). The lipid profile was determined by electrophotometric method. The experiment was done by using fully automated computerized chemistry analyzer Cobas c501 (Roche, Germany). Glucose was determined by spectrophotometric method. The experiment was performed using fully automatic computerized chemistry analyzer Cobas c501 (Roche, Germany). RBCs were counted by electrical impedance method. The experiment was done by using hematology analyzer Cell Dyn Ruby (Abbott, USA). LDL-C is calculated from the values of HDL-C, triglycerides (TG) and total cholesterol (TC) by using Friedewald formula as below:

$$
L D L=T C-H D L-T G / 5
$$

\section{Statistical analysis}

For statistical analysis SPSS 20 version was used. All the data were shown in Mean and Standard Error Mean $( \pm$ SEM). Online unpaired t-test was used for the calculation of $p$ value by matching Mean and SEM (Mean \pm SEM). The value of $p$ was consider significant statistically when $p<0.05$.

\section{RESULTS}

Total of 108 patients and 20 subjects as a control group were selected for the current study. The Mean \pm SEM of HbAlc, RBS, DBP and SBP of T2DM patients were compared with normal and identified that T2DM of effected individual have significantly greater value $(\mathrm{P}<0.05)$ compared to the HbA1c, RBS, DBP and SBP of normal or control subjects. And having some similarities with BMI scores but did not achieve statistical significance. The mean \pm SEM of lipid profile were also compared with control and found that T2DM patients have significantly higher $(\mathrm{P}<0.05) \mathrm{TG}, \mathrm{TC}, \mathrm{HDL}$ and LDL compared to TC, TG, HDL and LDL of normal or controlled (Table I). Six based analysis of the current study showed that males have higher value $(\mathrm{P}<0.05)$ ofHbA1c, TC and HDL paralleled to females patients. Female individuals showed higher $(\mathrm{p}<0.05)$ SBP and BMI paralleled to male. There is no difference found between LDL, TG and DBP of males and females (Table II). The T2DM patients were 
Table I. Comparative analysis of HbA1c, RBS, BMI, blood pressure and lipid profile of T2DM patients and control individuals.

\begin{tabular}{llll}
\hline Parameters & $\begin{array}{l}\text { Effected individuals }(\mathbf{n}=\mathbf{1 0 8}) \\
\text { Mean } \pm \text { SEM }\end{array}$ & $\begin{array}{l}\text { Patients }(\mathbf{n}=\mathbf{2 0}) \\
\text { Mean } \pm \text { SEM }\end{array}$ & P value \\
\hline $\mathrm{HbAlc}(\%)$ & $9.0 \pm 0.17$ & $5.4 \pm 0.08$ & $0.0001^{* * * *}$ \\
$\mathrm{RBS}(\mathrm{Mg} / \mathrm{dl})$ & $249.6 \pm 8.73$ & $108.7 \pm 4.24$ & $0.0001 * * * *$ \\
$\mathrm{TG}(\mathrm{Mg} / \mathrm{dl})$ & $208.8 \pm 9.60$ & $162.9 \pm 15.45$ & $0.0512^{* *}$ \\
$\mathrm{TC}(\mathrm{Mg} / \mathrm{dl})$ & $184.5 \pm 3.70$ & $161.1 \pm 4.76$ & $0.0094 * * *$ \\
$\mathrm{HDL}(\mathrm{Mg} / \mathrm{dl})$ & $38.30 \pm 0.87$ & $34.7 \pm 2.03$ & 0.1066 \\
$\mathrm{LDL}(\mathrm{Mg} / \mathrm{dl})$ & $102.7 \pm 2.86$ & $94.4 \pm 5.32$ & 0.2415 \\
$\mathrm{SBP}(\mathrm{mmHg})$ & $131.5 \pm 1.55$ & $120.0 \pm 0.00$ & $0.0019 * * *$ \\
$\mathrm{DBP}(\mathrm{mmHg})$ & $84.0 \pm 0.80$ & $80.0 \pm 0.00$ & 0.0357 \\
$\mathrm{BMI}\left(\mathrm{Kg} / \mathrm{m}^{2}\right)$ & $27.1 \pm 0.43$ & $25.4 \pm 0.53$ & 0.1029 \\
\hline
\end{tabular}

HbA1c, Glycated Hemoglubin; RBS Random Blood Sugar; BMI, Body mass index; TC, Total Cholesterol: TG, Triglycerides; DBP, Diastolic blood pressure; HDL, High density lipoprotein; SBP, Systolic blood pressure; LDL, Low density lipoprotein; *Indicate statistical significance.

Table II. Comparison of Age, HbA1c, RBS, lipid profile, SBP, DBP and BMI of male diabetic patients with control male subjects. The value are in Mean \pm SEM.

\begin{tabular}{|c|c|c|c|c|}
\hline \multirow[t]{2}{*}{ Parameters } & \multicolumn{2}{|c|}{ Male } & \multicolumn{2}{|c|}{ Female } \\
\hline & Normal $(n=11)$ & Patients $(n=56)$ & Normal $(n=9)$ & Patients $(n=52)$ \\
\hline Age (In years) & $44.82 \pm 2.77$ & $51.14 \pm 1.64$ & $45.22 \pm 1.72$ & $49.75 \pm 1.49$ \\
\hline HbA1c (\%) & $5.264 \pm 0.13$ & $9.056 \pm 0.24 * * * *$ & $5.578 \pm 0.11$ & $8.92 \pm 0.25 * * * *$ \\
\hline RBS (Mg/dl) & $99.27 \pm 5.80$ & $255.3 \pm 10.69 * * * *$ & $120.2 \pm 3.70$ & $243.5 \pm 14.09^{* * *}$ \\
\hline TG (Mg/dl) & $169.5 \pm 28.17$ & $202 \pm 12.1$ & $154.8 \pm 5.66$ & $216.1 \pm 15.14$ \\
\hline $\mathrm{TC}(\mathrm{Mg} / \mathrm{dl})$ & $154.7 \pm 7.70$ & $180.3 \pm 4.84^{*}$ & $168.9 \pm 3.83$ & $189 \pm 5.63$ \\
\hline HDL (Mg/dl) & $28.82 \pm 1.80$ & $38.04 \pm 1.38^{* *}$ & $41.78 \pm 2.32$ & $38.56 \pm 1.05$ \\
\hline LDL (Mg/dl) & $92.55 \pm 9.04$ & $96.7 \pm 4.08$ & $96.6 \pm 4.77$ & $109.1 \pm 3.84$ \\
\hline SBP (mmHg) & $121.7 \pm 0.78$ & $130.7 \pm 1.88^{*}$ & $120 \pm 0$ & $132.4 \pm 2.53^{*}$ \\
\hline DBP (mmHg) & $80 \pm 0.26$ & $83.05 \pm 1.09$ & $80 \pm 0$ & $85 \pm 1.19$ \\
\hline $\mathrm{BMI}\left(\mathrm{Kg} / \mathrm{m}^{2}\right)$ & $24.73 \pm 0.77$ & $26.34 \pm 0.59$ & $26.22 \pm 0.64$ & $27.88 \pm 0.61$ \\
\hline
\end{tabular}

HbA1c, Glycated Hemoglubin; RBS, Random Blood Sugar; TG, Triglycerides; TC, Total Cholesterol; HDL, High density lipoprotein; LDL, Low density lipoprotein; SBP, Systolic blood pressure; DBP, Diastolic blood pressure; BMI, Body mass index; *Indicate statistical significance.

Table III. Comparative analysis of stroke, angina, IHD and microvascular complications on the basis of $\mathrm{HbA1c}$

\begin{tabular}{lll}
\hline Parameters & HbA1c $\leq \mathbf{7 n = 1 8}$ & HbA1c $>\mathbf{7 n = 9 0}$ \\
\hline Stroke & $33.33 \%$ & $26.66 \%$ \\
Angina & $16.66 \%$ & $4.44 \%$ \\
IHD & $11.11 \%$ & $2.22 \%$ \\
Microvascular & $16.66 \%$ & $27.77 \%$ \\
complications & & \\
\hline
\end{tabular}

grouped based on HbA1c level (HbAlc $\leq 7$ and HbAlc $>7$ ). The patients $(\mathrm{HbA} 1 \mathrm{c} \leq 7)$; Stroke, Angina, IHD and
Microvascular complications were recorded as 33.33\%, $16.66 \%, 11.11 \%$ and $16.66 \%$ respectively. In patients $($ HbA1c > 7) stroke $(26.66 \%)$, angina $(4.44 \%)$, IHD $(2.22 \%)$ and microvascular complications $(27.77 \%)$ were recorded (Table III).

\section{DISCUSSION}

The current work revealed that patients of T2DM showed severe dyslipidemia and less control of glucose and having higher value $(\mathrm{p}<0.05)$ of HbA1c, RBS, DBP, SBP, TG, TC, HDL and LDL as compared to normal individuals. The current work were supported by other 
studies proposed in Pakistan (Hassan et al., 2004) India (Naeem et al., 2016) and Saudi Arab (Elinasri and Ahmed, 2008) which also reported, showed higher value $(\mathrm{p}<0.05)$ of HbAlc, RBS, DBP, SBP, TG, TC, HDL and LDL in T2DM compared to the normal population. Increased values of all these parameters suggest that DM patients must have cardiovascular complications. In the current work DBP and SBP were relatively very high $(\mathrm{p}<0.05)$ in effected individuals paralleled to normal individuals. Our work were also supported by other researcher, which showed relatively higher value $(\mathrm{p}<0.05)$ of SBP and DBP in effected individuals compared to control individuals (Prabodh et al., 2012). Females were found to be more hypertensive and hyperlipidemia have significantly higher $(\mathrm{p}<0.05) \mathrm{TG}, \mathrm{TC}, \mathrm{LDL}, \mathrm{SBP}, \mathrm{DBP}$ as compared to TG, TC, LDL, SBP and DBP of male patients. Similarly, previous studies also reported significantly higher $(\mathrm{p}<0.05) \mathrm{TG}, \mathrm{TC}$, LDL, SBP and DBP in female patients compared to male patients. No difference was observed in HDL in the present study. Other studies also supported the above statement except TG which has high value in male (Nyamdorj et al., 2018). Reduction in HbA1c is associated with better lipid parameters and improved insulin sensitivity in Type 2 DM (Sanghani et al., 2013).

\section{CONCLUSION}

Most of the T2DM patients have poor glycemic control. T2DM patients are more hypertensive. HbA1c can be used as a potential biomarker to predict cardiovascular disease (CVD) and dyslipidemia. $\mathrm{HbA1c}>7$ will raise Microvascular complication in T2DM patients. Female patients have more lipid abnormality than male but male patients were found to have poor glycemic control than female.

\section{ACKNOWLEDGEMENTS}

We are thankful to Mr. Hizbur Rahman lecturer in Zoology, Government Degree College Daggar Buner and Mr. Taj Muhammad (Pathologist) for their kind suggestion and cooperation in this work.

Statement of conflict of interest

The authors have declared no conflict of interest.

\section{REFERENCES}

American Diabetes Association. 2004. Nutrition principles and recommendations in diabetes (Position Statement). Diabetes Care, 27(Suppl. 1): 36-46. https://doi.org/10.2337/diacare.27.2007.S36
Boon, N.A. (Ed.). 2006. Davidson's principles and practice of medicine. Churchill Livingstone Elsevier Edinburgh. pp. 1320.

Cheng, D., 2005. Prevalence, predisposition and prevention of type II diabetes. Nutri. Metabol., 2: 29-34.

Elinasri, H.A. and Ahmed, A.M., 2008. Patterns of lipid changes among type 2 diabetes patients in Sudan. East Mediterr. Hlth. J., 14: 314-324.

Fabbrini, E., Sullivan, S. and Klein, S., 2010. Obesity and nonalcoholic fatty liver disease: biochemical, metabolic, and clinical implications. Hepatology, 51: 679-689. https://doi.org/10.1002/hep. 23280

Gotto, A.J., 2007. Cardiologist role in improving glucose control and global cardiovascular risk in with type 2 diabetes. Am. J. Cardiol., 4: 3-5. https:// doi.org/10.1016/j.amjcard.2006.11.001

Hammed, I.K., Abed, B.A. and Rashid, N.F., 2012. Glycated hemoglobin as a dual biomarker association between $\mathrm{HbAlc}$ and dyslipidemia in type 2 diabetic patients. J. Fac. Med. Baghdad, 54:88-92.

Hasan, Z.U., Zia, S. and Maracy, M., 2004. Baseline disease knowlegde assesment in patients with type 2 diabetes in a rural area of north west of Pakistan. J. Pakistan med. Assoc., 54: 67-72.

International Expert Committee report on the role of the A1c in the diagnosis of Diabetes. 2009. Diabetes Care, 32: 1327-1334. https://doi.org/10.2337/dc099033

Kannel, W.B., 1985. Lipids, diabetes, and coronary heart disease: insights from the Framingham Study. Am. Heart J., 110: 1100-1107. https://doi. org/10.1016/0002-8703(85)90224-8

Kannel, W.B., McGee, D.L., 1979. Diabetes and cardiovascular disease. The Framingham study. $J$. Am. med. Assoc., 241: 2035-2038.

Muhammad, N., Rehman, M.K., Mat-ur-Rehman and Muhammad, N.K., 2015. The role of glycated hemoglobin (HbAlc) and serum lipid profile measurements to detect cardiovascular diseases in type 2 diabetic patients. South East Asia J. Publ. Hlth., 23: 1-5. https://doi.org/10.3329/seajph. v5i2.28310

Naeem, M., Khattak, R.M., Ur-Rehman, M., 2016. The role of glycated hemoglobin (HbAlc) and serum lipid profile measurements to detect cardiovascular diseases in type 2 diabetic patients. S. East Asia J. Pub. Hlth., 5: 30-34.

Nyamdorj, R., Qiao, Q., Söderberg, S., Pitkäniemi, J., Zimmet, P. and Shaw, J., 2008. Comparison of body mass index with waist circumference, waist-tohip 
ratio, and waist-to-stature ratio as a predictor of hypertension incidence in Mauritius. J. Hypertens., 26: $866-870$.

Prabodh, S., Sripad, D.V., Chowdary, N.V.S. and Shekhar, R., 2012. Hypertension and dyslipidemia in type 2 diabetes mellitus patients of guntur and krishna districts in andhra pradesh, India. Nat. J. Lab. Med., 1: 7-10.

Sanghani, N.B., Parchwani, D.N., Palandurkar, K.M., Shah, A.M. and Dhanani, J.V. 2013. Impact of lifestyle modification on glycemic control in patients with type 2 diabetes mellitus. Indian J. Endocr. Metab., 17: 1030-1039. https://doi. org/10.4103/2230-8210.122618

Sankha, S., 2016. Estimation of HbA1c.FBS,TG and TC in subjects with TypeII diabetes mellitus. Indian $J$. appl. Res., 6: 130-133.

Tchernof, A. and Despres, J.P., 2013. Pathophysiology of human visceral obesity. Physiol. Rev., 1: 359404. https://doi.org/10.1152/physrev.00033.2011

Uribarri, J. and Tuttle, K.R., 2006. Advanced glycation end products and nephrotoxicity of high protein diets. Clin. J. Am. Soc. Nephrol., 1: 1293-1299. https://doi.org/10.2215/CJN.01270406

Uttra, K.M., Devrajani, B.R., Shah, S.Z.A., Devrajani, T., Das, T., Raza., S. and Naseem. 2011. Lipid profile of patients with diabetes mellitus (a multidisciplinary study). World appl. Sci. J., 12: 1382-1384.

Warnick, G.R., Knopp, R.H., Fitzpatrick, V. and Branson, L., 1990. Estimating low density lipoprotein cholesterol by the Feidewald equation is adequate for classifying patients on the basis of nationally cut points. Clin. Chem., 1: 9-15.

World Health Organization. 2013. The top 10 causes of death fact sheet No. 310. World Health Organization. Geneva, Switzerland:

Yadav, M.K., Mohapatra, T.K., Mohapatra, R.K., Khandhadiya, K., Firdoush, K.A. and Yadav, K.P., 2015. Study on glycated hemoglobin and lipid profile in Type-2 diabetes mellitus. Int. J. Sci. Res., 253: 166-06. 